KONSEP PSIKOLOGI TRANSPERSONAL

MENURUT ABU HAMID MUHAMMAD AL-GHAZALI.

\author{
Abdul Muhaya \\ UIN Walisongo Semarang \\ Email: abdulmuhaya@walisongo.ac.id
}

\begin{abstract}
Transpersonal psychology is one of the schools of psychology that studies the highest potential of buman; such as the spiritual depth, mystical experience and the consciousness of the self beyond ego. According to Imam al-Ghazali, trans conditions can occur because the consciousness of human depends on the quality level of the human soul. The differences of the quality level of the soul will cause the differences in human consciousness. There are five quality levels of soul according to Imam Al-Ghazali: sensual, imaginative, rational, contemplative and holly consciousness. For al-Ghazali man has the ability to pass from a lower level of consciousness (consciousness acquired by reason) into higher self-esteem: the consciousness that occurs in the self beyond the rational ego (self-beyond Ego). Furthermore Al-Ghazali states that humans have the ability to explore the area beyond reason (Thur wara 'al-Aql). In this condition, bumans are able to know the objects that were originally not able to be known by reason by purveying and sharpening the drauq
\end{abstract}

Keywords: Transpersonal, self beyond ego

\begin{abstract}
Abstrak
Psikologi transpersonal adalah salah satu madzhad dari psikologi yang mempelajari tentang potensi yang paling tinggi dari manusia; seperti pengalaman trans yang dialami oleh manusia, penalaman spiritual, pengalaman mistik dan hal-hal yang berkaitan dengan kesadaran yang berada diatas ego (self beyond ego). Menurut Imam al-Ghazali, kondisi trans dapat terjadi karena pada dasarnya kesadaran itu tergantung pada tingkatakan ruh yang menerima persepsi. Perbedaan tingkatan ruh yang menjadi tempat terjadinya kesadaran menjadikan seseorang dapat memiliki perpindahan kesadaran mulai dari kesadaran yang bersifat indrawi, imaginatif, rasional, fikri dan qudsi. Bagi al-Ghazali manusia punya kemampuan untuk melintas dari kesadaran yang rasional (kesadaran yang
\end{abstract}


diperoleh oleh akal) kedalam kesandaran yang lebih tinggi lagi: yaitu kesadaran yang terjadi pada diri diluar ego rasional (self- beyond Ego). Kesadaran tersebut disebabkan manusia memiliki kemampuan menjelajah wilayah diluar akal (Thur wara' al-Aql). Pada kondisi ini, manusia mampu mengetahui objek yang semula tidak mampu diketahui oleh akal. Bagi alGhazali, penjelajahan self-beyond ego dapat dilakukan dengan mempertajam dzauq

Keywords: Transpersonal, self beyond ego

\section{A. LATAR BELAKANG PENELITIAN}

Mensintesakan antara khazanah filsafat Timur dan filsafat Barat merupakan issu yang menarik untuk dibahas. Dalam penelitian ini, peneliti akan mendampingkan dan memadukan konsep psikologi transpersonal Barat dengan konsep spritualitas yang ada pada budaya Timur, khususnya yang telah dijabarkan oleh al-Ghazali dalam berbagai karyanya.

Psikologi transpersonal adalah salah satu madzhad dari psikologi yang mempelajari tentang potensi yang paling tinggi dari manusia; seperti pengalaman trans yang dialami oleh manusia, penalaman spiritual, pengalaman mistik dan hal-hal yang berkaitan dengan kesadaran yang berada diatas ego (self beyond ego). S.I. Shapiro, Grace W. Lee dan Philippe L. Gross telah mengadakan penelitian dari karya transpersonal yang berbahasa Inggris mulai tahun 1991 samapai dengan th. 2001. Mereka menyatakan bahwa telah ditemukan 80 macam definisi dari transpersonal psikologi dan bahkan secara teliti mereka membuat persentase tabel penggunaan istilah yang paling sering digunakan oleh para ahli; yaitu seperti term transendensi, spiritualitas dan lain sebagainya. ${ }^{1}$ Sebelumnya, Lajoie dan Shapiro telah mereview sekitar empat puluh definisi dari

111 S.I. Shapiro and other. The International Journal of Transpersonal Studies, "The Essence of Transpersonal Psychology Contemporary Views. 2002, Vol. 21. 19-31. 
trnspersonal psikologi yang telah tertera dalam literatur yaang beredar semenjak tahun 1969 to 1991. Mereka menemukan bahwa ada lima kata kunci penting dalam defenisi tersebut : states of consciousness, higher or ultimate potential, beyond the ego or personal self, transcendence, dan the spiritual. ${ }^{2}$

Paling tidak ada beberapa isu penting yang menjadi kajian pokok dari ilmu ini; yaitu perkembangan kesadaran diri, kesadaran diluar ego, pengalaman puncak, pengalaman mostik, tingkatan tingkatan trans dan berbagai pengalaman batin yang lainnya. ${ }^{3}$

Dari segi keilmuan, psikologi transpersonal dianggap sebagai aliran psikologi yang relatif baru. Meskipun demikian, ilmu ini mereupakan pengembangan dari psikologi sebelumnya; yaitu psikoanalisis, behavioris dan humanistik. Oleh karena itu, para ahli sering menyebutkan bahwa psikologi transpersonal merupakan madzhab keempat dalam perkembangan psikologi. ${ }^{4}$ Meskipun pembahasan aspek spiritualitas sudah muncul pada madzhad psikologi sebelumnya, sepert i bahasan yang disampaikan oleh William James, Carl Jung dan Otto Rank, akan tetapi menurut Miller psikolog yang telah lampau cenderung melupakan dimensi spiritual yang dicapai oleh manusia.

Psikologi transpersonal, pertama, bermula dari pengalaman luar biasa para hippies pencetus revolusi kebudayaan Amerika di tahun 60-an. Para hippies yang menolak kemapanan itu melakukan proses kembali ke alam meninggalkan kehidupan modern dan mengikuti kehidupan primitif suku Indian yang para dukunnya gemar mencari kebenaran dengan menghisap jamur-jamur halusinogen yang membuat halusinasi yang dianggap sebagai kebenaran. Kedua, fenomena maraknya para cendekia

\footnotetext{
${ }^{2}$ Wikipedia, the free encyclopedia

${ }^{3}$ Ibid.

${ }^{4}$ Jalaluddin Rahmad dalam artikelnya "SQ: Psikologi Dan Agama" dalam pengantar buku Donah Zohar dan Ian Marshall. SQ Memanfaatkan Kecerdasan Spiritual dalam Berfikir Integralistik dan Holistik untuk. Memaknai Kehidupan. Bandung, Mizan, tt.
} 
muda di Amerika Serikat yang cenderung meggunakan obat psiko-tropika bahkan banyak diantara mereka yang kecanduan, meskipun dalam bayang - bayang ancaman hukumam yang berat serta hilangnya pekerjaan. ${ }^{5}$

Tampaknya, psikologi lama tidak dapat menjelaskan fenomena tersebut, sehingga muncul aliran baru; yaitu psikologi transpersonal. Dengan kata lain, psikologi transpersonal merupakan aliran psikologi yang kecewa terhadap ketidakpekaan pakar psikologi terdahulu dalam menangkap peran spiritual dalam diri individu. Kehilangan sensibilitas pada peran itu, mengakibatkan ketidakmampuan referensi psikologi tiga mazhab sebelumnya untuk mengungkap fenomena kesehatan mental secara tuntas. Psikologi Transpersonal sebagai sintesa dari Psikologi Timur tradisional dan psikologi Barat Modern. Jika dalam psikologi modern jiwa dianggap sebagai fungsi dari proses otak yang material, Psikologi tradisional menganggap yang material adalah komponen terrendah, sedangkan jenjang tangga tertingginya adalah spiritual ( self beyond-ego). Jenjang kesadaran ini sejajar dengan jenjang realitas di mana dunia material adalah anak tangga terbawahnya dan spiriyual merupakan realitas yang paling tinggi dari kesadaran yang dimiliki oleh manusia.

Diantara tokoh psikologi yang dianggap sebagai bapak psikologi transpersonal antara lain adalah William James, Carl Jung, Otto Rank, Abraham Maslow dan Roberto Assagioli. Secara historis, William James telah menyebutkan terma transpersonal pada kuliahnya di Harvard University pada tahun 1905-1906. Selanjutnya Abraham Maslow juga menyinggung persoalan tersebut ketika menjelaskan persoalan yang berkaitan dengan peak experiences yang dialami oleh manusia. Selanjutnya Stanisly Grof dan Viktor Frankl menganjurkan istilah psikologi transpersnal untuk menyebut ilmu baru ini. Pada tahun 1969,

${ }^{5}$ Charles T. Tart. Transpersonal Psychologies. Harper, New York 1969. 
Abraham Maslow, Stanislav Grof dan Anthony Sutich merupakan tokoh yang mendorong terbitnya The Journal of Transpersonal Psychology, sebuah jurnal yang paling terdepan dalam bidang psikologi transpersonal. Setelah itu, berdirilah Association for Transpersonal Psychology (ATP) pada tabun 1972. Berikut adalah nama - nama orang yang pernah menjadi presiden dari Assosiasi tersebut: Alyce Green, James Fadiman, Frances Vaughan, Arthur Hastings, Daniel Goleman, Robert Frager, Ronald Jue, Jeanne Achterberg dan Dwight Judy. ${ }^{6}$ Selanjutnya pada tahun 1980s dan 90an muncullah para penulis penting dalam area studi baru ini; seperti Jean Houston, Stanislav Grof, Ken Wilber, Michael Washburn, Frances Vaughan, Roger Walsh, Stanley Krippner, Michael Murphy, Charles Tart, David Lukoff, Vasily Nalimov, Margret Rueffler dan Stuart Sovatsky. Dan selanjutnya kajian keilmuan ini dikembangkan dalam institusi formal; seperti The Institute of Transpersonal Psychology (US), California Institute of Integral Studies (US), John F. Kennedy University (US), Saybrook University (US), University of West Georgia (US), Atlantic University (US), Burlington College (US), Essex University (UK), Liverpool John Moores University (UK), the University of Northampton (UK), Leeds Metropolitan University (UK), Naropa University (Colorado).

Sayangnya, kegairahan intelektual yang berkaitan dengan psikologi transpersonal masih belum menjalar ke dunia Islam. Padahal jika ditelusuri penjelasan tentang pengalaman spiritual dan pengalaman transendensi serta pengalaman mistik yang menjdi objek kajian dari madzhab psikologi transpersonal dapat ditemukan dalam berbagai literature; khususnya adalah literatur tasawuf;seperti al- Risalah Qusyairiyah karya Abdul Karim Hawazin al-Qusyairi, Bayan al-Farq Bain Shadr wa al-

\footnotetext{
${ }^{6}$ Wikipedia, the free encyclopedia
} 
Qalb wa al-Fuad wa al- Lubb karya Hakim al-Tirmidzi, Kasyf al-Mabjub karya Al-Hujwiri dan lain sebagainya. Meskipun demikian elaborasinya masih berserakan dan cenderung bersifat mistis- magis.

Ada beberapa alasan mengapa penelitian ini difakuskan dalam karya al-Ghazali. Pertama, al-Ghazali merupakan intelektual muslim yang memilki reputasi keilmuan yang multi demensional. Disamping seorang sufi, al-Ghazali juga terkenal sebagai filofos dan teolog serta fuqaha' ${ }^{7}$ yang cenderung berfikir logis, sehingga al-Ghazali dalam berbagai karyanya alGhazali dapat menjelaskan lebih jelas tentang persoalan yang bersifat spiritual yang oleh sebagian mistikus cenderung dianggap sebagi persoalan mistis yang sulit di jelaskan dengan kata -kata.

Kedua, al-Ghazali disamping sebagai seorang penulis juga merupakan pelaku dari berbagai penglaman yang dijadikan sebagai objek kajian dari psikologi transpersonal. Bahkan pengalaman self beyond ego ini dialaminya dalam fase akhir dari periode perjalanan intelektualnya dan sekaligus menjadi pengobat atas ketidak puasan intelektualnya yang pernah dialami ketika dia menginginkan kebenaran yang hakiki ( al-Ilm al-Yaqin $)^{8}$.

Ketiga, al-Ghazali telah membahas sebagaian besar dari bahasan penting yang menjadi objek kajian dari psikologi transpersonal secara terpisah; seperti bahasan tentang tingkatan kesadaran manusia dalam kitabnya Misykat al-Anwar, cara menembus jenjang spiritualitas dalam karyanya Mi'raj al-Salikin, berbagai pengalaman mistis bagi al-wasilun ila Allah dalam kitabnya Ibya' Ulum al-Din dan juga pengalaman transedensi dalam kitabnya Al-Munqidh Min al-Dhalal, Misykat al-Anwar dan juga Ibya' Ulum al-Din.

\footnotetext{
${ }^{7}$ Abd al-Aziz Izzu al-Din dalam Muqadimah Misykeat Al-Anwar Wa Mushafat al-Asrar li Al Imam al-Ghazali. Alam al-Kutub. Bairut, tt.

${ }^{8}$ Lihat Abu Hamid Muhammad Al-Ghazali al-Munqidh Min al-Dhalal Alam al-Kutub. Bairut, tt.
}

Abdul Muhaya, Konsep Psikologi Transpersonal... 
Dari latar belakang diatas, maka peneliti tertarik untuk melakukan penelitian dengan judul Konsep Psikologi Transpresonal Menurut alGhazali.

\section{B. RUMUSAN MASALAH.}

Penelitian ini akan membahas konsep Al-Ghazali tentang psikologi transpersonal. Oleh karena itu, fokus masalah dari penelitian ini adalah bagaimankah formulasi konsep psikologi transpersonal dalam karya alGhazali. Dari pertanyaan inti tersebut maka terdapat rumusan masalah dari penelitian sebagai berikut:

1. Apa dan bagaimanakah konsep self beyond-ego menurut al-Ghazali ?

2. Bagaimanakah cara seseorang dapat memasuki wilayah self beyond-ego tersebut.

3. Apa sajakah yang dialami oleh manusia ketika dia berada dalam kondisi tersebut.

Dari jawaban tiga pertanyaan penting diatas akan diperoleh gambaran yang jelas tentang konserp psikologi transpersonal menurut al-Ghazali.

\section{TUJUAN DAN SIGNIFIKANSI PENELITIAN}

Penelitian ini bertujuan untuk mengungkap dan mengetahui konsep psikologi transpersonal Al-Ghazali, sehingga penemuan tersebut dapat menjelaskan bahwa sesungguhnya konsep psikologi transpersonal bukan barang baru sebagaimana yang dikemukakan oleh para pakar psikologi Barat, akan tetapi al-Ghazali yang hidup pada awal abad ke XI masehi telah berhasil menjelaskan pengalaman spiritual, pengalaman mistik serta pengalaman trancedensi serta pengalaman rohaniah yang 
dialami oleh manusia dalam penjelasan ilmiah sehingga hal-hal tersebut tidak hanya merupakan pengalaman bagi orang tertentu, akan tetapi menjadi pengalaman yang terbuka bagi siapapun yang mampu mengoptimalkan potensi yang telah dimiliki oleh manusia.

Penelitian ini memiliki signifikansi yang besar utamanaya adalah jika dikaitkan dengan keilmuan. Sebab, penelitian ini berusaha untuk mensintesakan wacana tasawuf klasik dengan psikologi Modern Barat.. Disamping itu, jika dikaitkan dengan keberadaan jurusan TasawufPsikoterapi yang ada di fakultas Ushuluddin maka penelitian merupakan upaya untuk memperkaya dan sekaligus memperkuaat eksistensi jurusan tersebut, utamanya dalam pengayaan pengetahuan.

\section{DESAIN OPERASIONAL}

Banyak orang mengira bahawa pengalaman mistik yang dialami oleh para sufi merupakan pengalaman yang sulit digambarkan dan sekaligus merupakan anugerah yang datang ( pemberian) dari Allah. Kesan yang demikian ini merupakan akibat dari penjelasan yang sering ditemukan dalam kitab tasawuf. Hal yang demikian ini menjadikan pengalaman trans, pengalaman mistik dan pengalaman spiritual menjadi sesuatu yang lebih banyak berfisat mistis-magis yang sulit dijabarkan dengan kata-kata. Bahkan dari segi perolehannya seolah merupakan hak Allah sedangkan manusia tinggal menerima. Pemahaman yang semacam ini akan berubah jika kita mencermati penjelasan yang dikemukakan oleh Imam al-Ghazali. Sebab, Imam al-Ghazali sangat pintar dalam memaparkan pengalaman spiritual dan berikut penjelasana persoalan yang harus dilakukan oleh seorang untuk memperolehnya. Disamping itu, alGhazali juga telah memberikan penjelasan tentang wilayah akal ( Thur alAql) dan juga menyebut ada wilayah lain yaitu wilayah self beyond ego ( Thur 
wara' al-Aq). Barangkali, ini merupakan akaibat dari kecemerlangan alGhazali dalam bidang ilmu lain, khususnya adalah filsafat yang cendderung mengunakan nalar logis sebagai dalil.

Pada intinya, semangat dari timbulnya psikologi transpersonal adalah adanya doronggan keingintahuan yang kuat tentang persoalan spiritualitas yang dialami oleh manusia; seperti pengalaman mistik, pengalaman spiritual, fana', baqa', dan lain sebagainya. Ditangan para psikolog Barat, pengalaman tersebut diatas dijelaskan dengan bahasa psikologi Modern.

Dari penjelasan diatas dapat digambarkan bahwa desain operasional dari penelitian ini adalah peneliti mengambil the body of knowladge dari psikologi transpersonal dan selanjutnya ditampilkan konsep Imam al-Ghazali tentang unsur - unsur yang ada dalam psikologi transpersonal.

\section{E. TINJAUAN KEPUSTAKAAN}

Robert E. Ornstein dalam makalahnya yang berjudul Contemporery Sufism yang dipublikasikan oleh Charles T. Tart dalam bukunya Transpersonal Psychologies telah berupaya untuk menampilkan berbagai aspek -aspek tasawuf yang memiliki kaitan dengan persolan yang menjadi kajian dari psikologi transpersonal; seperti persoalan pengetahuan tertinggi, perjalana spiritual, dan berbagai nukilan dari berbagai dialog ahli sufi yang mengepresikan pengalaman spiritual dan pengalaman mistik. Meskipun demikian tulisan yang disajikan oleh Robert E Ornstein belum dapat mengambarkan secara gamblang tentang konsep psikologi transpersonal dalam wacana tasawuf dan belum menyinggung konsep psikologi transpersonalnya Imam al-Ghazali. 
Muh. In'amuzzahidin MAg. dalam Thesis yang berjudul Wali alMajdbub dan juga bukunya yang berjudul Wali Sufi Gila juga telah mengunakan psikologi transpersonal sebagai alat untuk memahami wacana kegilaan yang dialami oleh sebagian wali. Buku dan Thesis tersebut juga belum secara spisifik menggambarkan konsep psikologi transpersonal dalam wacana tasawuf.

Qadim Suseno, MSI dalam Thesisnya yang berjudul Epistemologi Menurut al-Ghazali juga telah membaahas persoalan yang berkaitan apa itu ilmu serta pembagian ilmu menurut al-Ghazali serta menyinggung persoalan altered states of counsciousnes dimana ilmu laduni diperoleh, akan tetapi Thesis tersebut belum membahas secara detail tentang bangunan psikologi transpersonal yang ada dalam karya al-Ghazali.

Dari paparan diatas diketahui bahwa penelitian dengan judul Konsep Psikologi Transpersonal Menurut al-Ghazali merupakan objek kajian penelitian yang belum diteliti oleh peneliti sebelumnya.

\section{F. METODE PENELITIAN}

\section{Jenis Penelitian.}

Penelitian ini merupakan penelitian literatur bukan penelitian lapangan. Oleh karena itu, seluruh data yang ada dalam penelitian ini bersumber pada kitab dan buku serta berbagai $t$ tulisan yang terkait dengan persoalan yang menjadi objek kajian dari penelitian ini.

\section{Sumber Data.}

Penelitian ini memiliki dua sumber data, yaitu sumber data primer dan sumber data sekunder. Sumber data primer berasal dari kitab - kitab tasawuf karya Imam al-Ghazali sebagai berikut: Ihya' Ulum 
al-Din, Al-Munqid Min al-Dhalal, Misykeat al-Anwar,Miraj al-Salikin, Kasyf Ulum al-Akbirah, Minhaj al-Abidin.

Sedangkan sumber data sekunder berasal dari buku- buku tasawuf dari karya ulama' selain al-Ghazali dan karya - karya yang lain yang berisi tentang persoalan yang menjadi kajian dari objek psikologi transpersonal; seperti Qut al-Qulub karya Abu Amr Al-Makki, Kasyf alMabjub karya Al-Hujwiri, A- l Risalah al- Qusyairiyah karya Imam alQusyairi dan juga Transpersonal Psychologies karya Charles T. Tart, Beyond Mind: Steps to a Metatranspersonal Psychology karya Capriles dan Fontana, David, Slack, Ingrid \& Treacy, Martin, Eds.dalam karyanya yang berjudul Transpersonal Psychology: Meaning and Developments.

3. Metode Pengumpulan data.

Penelitian ini merupakan penelitian literatur, karenanya penulusuran data hanya dilakukan melalui sumber-sumber yang berupa buku . Teks yang menjadi sumber penelitian ini baik yang bersifat primer maupun sekunder dibaca dan kemudian diklasifikasikan sesuai dengan karakter masing-masing dan selanjutnya diformulasikan dalam bentuk tulisan yang sistematis. Selanjutnya hasil dari formulasi tersebut dianalisis dan kemudian disimpulkan.

4. Metode Analisis Data.

Setelah data yang diperlukan dalam penelitian ini terkumpul secara sistematis, maka prosese selanjutnya adalah analisis data. Dalam penelitian ini, data yang ada akan dianalisis mengunakan konten analisis melalui pendekatan hermeneutika. Pendekatan hermeneutika yang digunakan dalam analisis ini bertujuan untuk memahami makna yang terkandung dalam teks. Mengingat teks yang digunakan dalam kitabkitab tasawuf yang menjadi sumber dari data penelitian ini bukanlah 
teks yang mandiri dan terbebas dari konteks, maka peneliti akan mengunakan Hermeniutika Psiko-historis; yaitu penafsiran yang berusaha memahami makna teks yang melibatkan aspek psikologis dan historis yang melatar belakangi munculnya teks, sehingga teks dapt difahami sebagaimana yang dimaksuk oleh penulisnya (al-Tbrab bi Khusush al-Sabab la bi Umum al-Lafdz) .

\section{G. TEMUAN}

Menurut al-Ghazali, perpindahan kondisi kesadaran dari satu kondisi ke kondisi yang lain ( transpersonal) dapat terjadi pada seseorang karena beberapa hal sebagai berikut:

1. Kondisi transpersonal dapat terjadi karena pada dasarnya kesadaran itu tergantung pada tingkatakan ruh yang menerima persepsi. Perbedaan tingkatan ruh yang menjadi tempat terjadinya kesadaran menjadikan seseorang dapat memiliki perpindahan kesadaran mulai dari kesadaran yang bersifat indrawi, imaginatif, rasional, fikri dan qudsi. Bagi al-Ghazali manusia punya kemampuan untuk melintas dari kesadaran yang rasional (kesadaran yang diperoleh oleh akal) kedalam kesandaran yang lebih tinggi lagi: yaitu kesadaran yang terjadi pada diri diluar ego rasional (self-beyond ego). Kesadaran tersebut disebabkan manusian memiliki kemampuan menjelajah wilayah diluar akal (Thur wara' al-Aql). Pada kondisi ini, manusia mampu mengetahui objek yang semula tidak mampu diketahui oleh akal. Bagi al-Ghazali, penjelajahan self-beyond ego dapat dilakukan dengan mempertajam dzauq: yaitu pemberian Allah untuk mengasosiasikan sesuatu yang bersifat spiritual

\footnotetext{
${ }^{9}$ Misykat, 166.
} 
dan kejiwaan (al-mauhibah fi al-musyarikah al-ruhiyah wa alnafsaniiyah). Baginya, jangkauan dzauq lebih kuat dibanding dengan aqal yang menghasilkan ilmu, sebab ilmu adalah hasil analogi sedangkan dzauq menemukan realitas objek. Dia menyatakan al-Ilm fauq al-Iman, al-Dzauq fauq al-ilm, fa alDzauq wujdan wa al-ilm qiyas.

2. Kondisi trans dapat pula terjadi karena manusia memiliki dua pintu kesadaran: Pertama adalah kesadaran yang berasal dari pintu lahir yang menghadap ke alam yang nyata dan kedua adalah pintu bathin yang menghadap ke alam ghaib (malakut). Pintu pertama sebagi sumber kesadaran yang terjadi ketika manusia mengamati objek yang manifes dalam alam nyata ini. Sedangkan pintu kedua berfungsi untuk mengenali realitas objek yang berada dalam alam metafisika. Lebih lanjut, alGhazali menjelaskan bahwa seseorang dapat mengalami trans dari suatu kondisi ke kondisi yang lain ddengan cara berlatih dan membiasakan secara sungguh-sungguh untuk memalingkan kecenderungan dan kecintaan yang dapat menyebabkan hati menjadi kotor atau terhijab dan selanjutnya menyiapkan diri untuk menerima iluminasi cahaya al-Haq.

3. Menurut al-Ghazali, alam metafisika yang menjadi sumber ilmu manusia dan kesadaran manusia terdiri dari malaikat dan iblis. Karena itu, kondisi trans dapat juga berasal dari iluminasi cahaya yang benar (malaikat) dan juga mungkin dari iblis dan syaithan. Secara umun dapat dikatakan bahwa jika mata hati seseorang bersih dari berbagai penyakit hati dan telah suci serta dihias dengan perilaku ketaqwaan maka trans yang dialami orang tersebut bersumber dari malaikat. Sebaliknya, 
jika trans terjadi pada orang yang hatinya kotor dan terhijab dengan dunia maka hal tersebut terjadi karena pengaruh syaithan. Baik alam fisika maupun maupun alam metafisika, dalam pandangan al-Ghazali, masing - masing memilki dua tingkatan: alam fisika adakalanya berwujud aqli ( persepsi yang ada pada jiwa / qalb) dan wujud imaginatif ( persepsi imaginatif), sedangkan alam metafisika tertiri dari tingkatan wujud realitas dan yang kedua adalah wujud yang ada dalam lauh al-maahfudz. Hubungan antara satu tingkatan dengan tingkatan yang lain merupakan hubungan kesatuan, sedangkan tingkatan yang ada merupakan tingkat gradasi dari hasil penangkapan manusia terhadap realitas tersebut.

4. Ada beberapa cara untuk mengalami kondisi trans. Pertama, sebagaimana yang dikemukakan oleh al-Ghazali dalam kitab Ihya', dengan melakukan mujahadah dan riyadhah dalam rangka mensucikan jiwa dari berbagai hal yang membuntu hubungan manusia dengan Realitas; yaitu harta benda, pangkat, taqlid dan ma'siyat. Dalam kitab Misykat al-Anwar, al-Ghazali menjelaskan bahwa dalam rangka mencapai kondisi trans tertinggi, seorang harus membuka hijab yang menghalangnya baik itu hijab kegelapan, hijab cahaya dan gelap mapun hijab yang berwujud cahaya.. Kondisi ttrans seseorang sanmgat tewrgantung pada adanya tirai ( hijab) yang menghalanginya.

Kedua, trans dapat diperoleh dengan cara meningkatkan kualitas jiwa utamanya adalah yang berkaitan dengan dzauq melalui kegiatan mendengarkan musik (al-sama'). Sebab, 
mendengarkan musik dapat menghantarkan pendemngarnya untuk sampai pada kondisi wajd (ekstasi).

5. Adapun pengalaman yang dirasakan adalah ekstasi ( wajd), tengelam dalam keindahan Realitas ( al-Haq), tengelam dalam keindahan secara mutlak dan tidak menyadari lagi dirinya sehingga yang ada hanyalah al-Haq. Pengalaman tersebut berimplikasi pada tingkat kejelasan dari ilmu yang diperoleh.

\section{REFERENSI}

Capriles, E. (in press). Beyond Mind III: Further Steps to a Metatranspersonal Pbilosophy and Psychology. Miami, Florida: The International Journal of Transpersonal Studies, special issue following vol. 25.

Cowley, Au-Deane S. \& Derezotes, David (1994) Transpersonal Psychology and Social Work Education. Journal of Social Work Education, 10437797, Winter, Vol. 30

Daniels, M. (2005). Shadow, Self, Spirit: Essays in Transpersonal Psychology.

Exeter: Imprint Academic.

Ferrer, Jorge N. (2001) Revisioning Transpersonal Theory. A Participatory Vision of Human Spirituality. New York: State University of New York Press (SUNY Series in Transpersonal and Humanistic Psychology)

Friedman, Harris (2000) Toward Developing Transpersonal Psychology as a

Scientific Field. Paper presented at Old Saybrook 2 conference, May 11-14, 2000, State University of West Georgia

Fontana, David, Slack, Ingrid \& Treacy, Martin, Eds. (2005) Transpersonal Psychology: Meaning and Developments. Transpersonal Psychology Review Special Issue. Leicester: British Psychological Society 
Al-Ghazali, Abu Hamid Muhammad bin Muhammad. Ibya' Ulum alDin. Indonesia: Dar Ihya', tt.

Mukasyafat al-qulub al-Muqarrib Ila Hadhrat Allah al-Ghuyub.

Kairo: Mathba'ah Muhammad Atif, tt.

Misykat al-Anwar Wa Mushafat al-Asrar. Bairut Alam al-

Kutub, tt.

Majmu'ah Rasail li al-Ghazali. Bairut: Dar al-Fikr, tt.

----------- Al-Munqidh min al-Dhalal. Bairut: Al Maktabah al-

Syu'biyah,tt.

Grof, Stanislav (1985). Beyond the Brain. Albany, New York: State University of New York Press.

Al-Hujwiri, Ali Bin Ustman al-Jullabi. Kasyf al-Mabjub. Bairut: Dar alNahdhah Al-Arabi.

Lajoie, D. H. \& Shapiro, S. I. (1992). Definitions of transpersonal psychology:

The first twenty-three years. Journal of Transpersonal Psychology, Vol. 24.

Al-Makki, Abu Thalib Muhammad Ibn Ali. Qut al-Qulubfi Mu'amalat alMabbub. Mujtaba Minowi, Wiesbaden, Frans Steiner.

Scotton, Bruce W, Chinen, Allan B. and John R. Battista, Eds. (1996) Textbook of Transpersonal Psychiatry and Psychology. New York: Basic Books

Al-Taftazani, Abu al-Wafa al-Ghanimi. Al-Madkhal Ila tasawuf al-Islami. Kairo: Dar al-Tsaqafah Li al-Nashr wa al-Tauzi', 1983.

Al-Thusi, Abu Nashr al-Sarrajj. Al-Luma'. Disunting oleh Abd al-Halim Mahmud dan Thaha Surur. Kairo: t.p. 1960.

Al-Tirmidzi, Abi Abdullah Muhammad Bin Ali al-Hakim. Bayan al-Farq Bain al-Shard wa al-Qalb wa al-Fuad wa al-Lubb. Kairo: Maktabah alKuliyyah al-Azhariyah, tt. 
Walsh, R. \& Vaughan, F. (1993). On transpersonal definitions. Journal of Transpersonal Psychology, 25 (2) 125-182

Washburn, Michael (1994). Transpersonal Psychology in Psychoanalytic Perspective. Albany, New York: State University of New York Press. A-Qusyairi, Abd al-Karim al-Hawazin. Al_risala al-Qusyairiyah Bairut Dar al-Khair, 2008. 